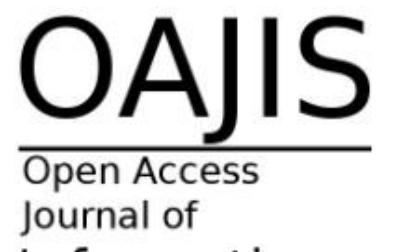

Information

Systems

is.its.ac.id/pubs/oajis/
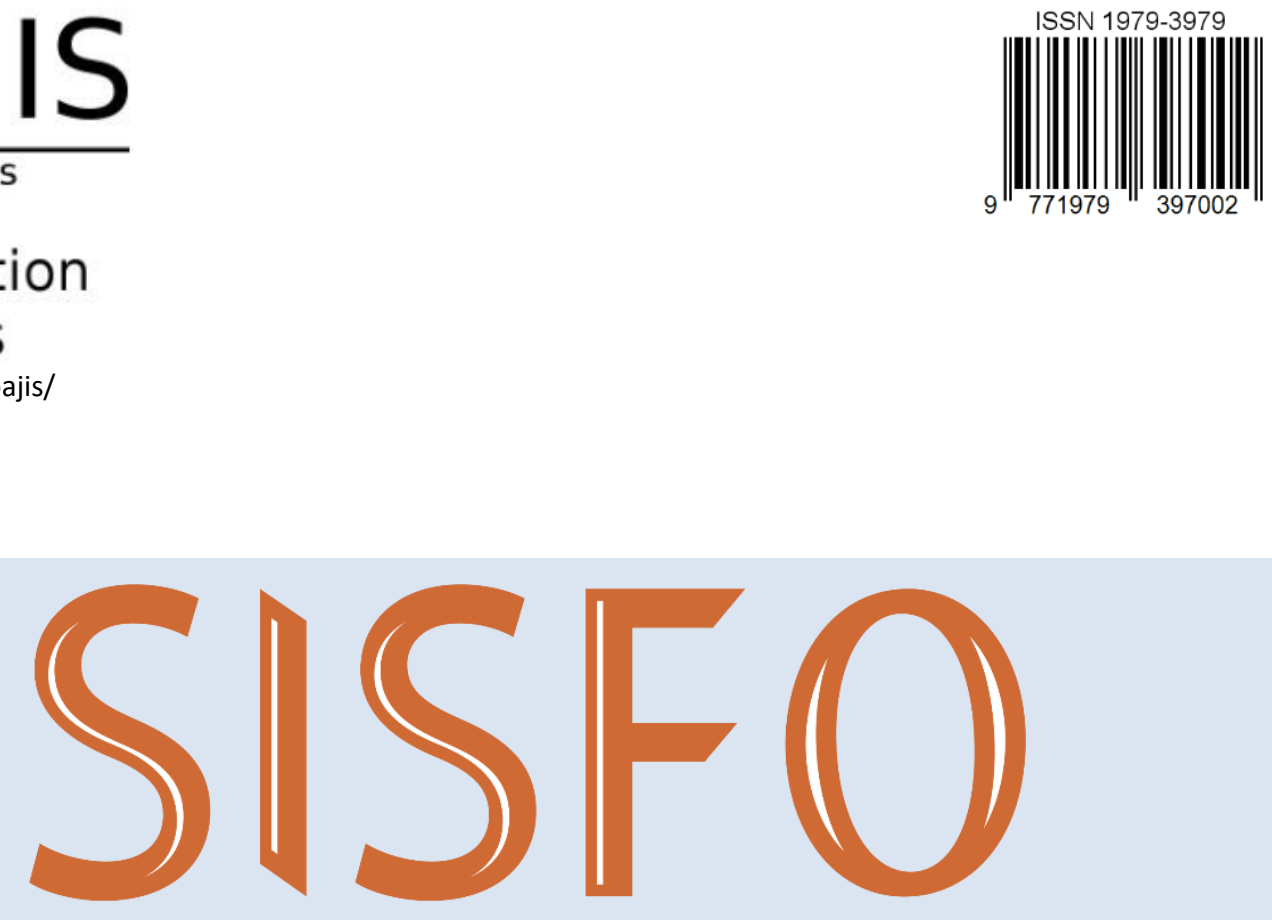

Inspirasi Profesional Sistem Informasi

\section{People}

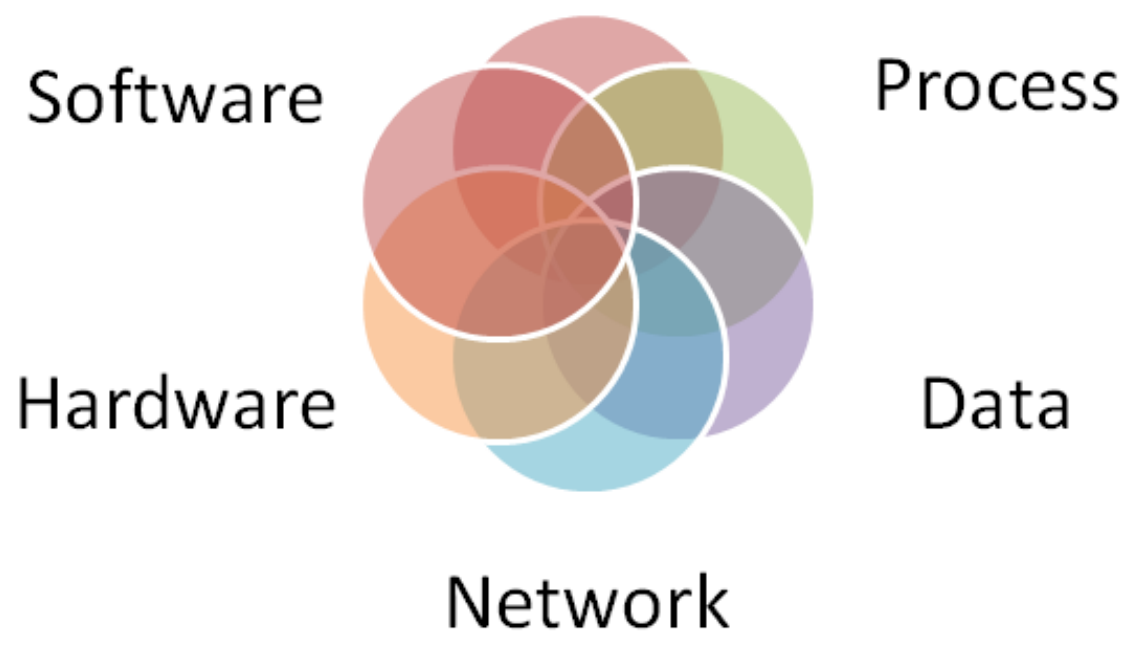


OAJIS

Journal of

Information

Systems

is.its.ac.id/pubs/oajis/

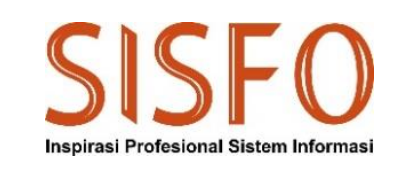

Jurnal Sisfo Vol. 08 No. 02 (2019) i-ii

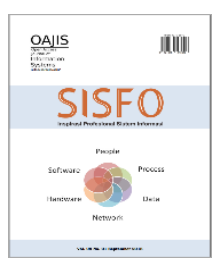

\section{Pimpinan Redaksi}

Faizal Mahananto

\section{Dewan Redaksi}

Eko Wahyu Tyas Darmaningrat

Amna Shifia Nisafani

Arif Wibisono

Rully Agus Hendrawan

\section{Tata Pelaksana Usaha}

\section{Achmad Syaiful Susanto}

Rini Ekowati

\section{Sekretariat}

Departemen Sistem Informasi - Fakultas Teknologi Informasi dan Komunikasi

Institut Teknologi Sepuluh Nopember (ITS) - Surabaya

Telp. 031-5999944 Fax. 031-5964965

Email: editor@jurnalsisfo.org

Website: http://jurnalsisfo.org

Jurnal SISFO juga dipublikasikan di Open Access Journal of Information Systems (OAJIS)

Website: http://is.its.ac.id/pubs/oajis/index.php 
OAJIS

Journal of

Information

Systems

is.its.ac.id/pubs/oajis/

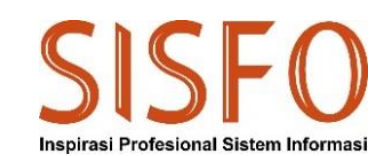

Jurnal Sisfo Vol. 08 No. 02 (2019) i-ii

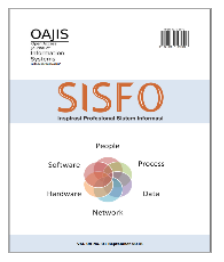

\section{Mitra Bestari}

Satria Fadil Persada, S.Kom., M.BA., Ph.D. (Institut Teknologi Sepuluh Nopember)

Sholiq, S.T., M.Kom., M.SA. (Institut Teknologi Sepuluh Nopember)

Nur Aini Rakhmawati, Ph.D. (Institut Teknologi Sepuluh Nopember)

Retno Aulia Vinarti, Ph.D. (Institut Teknologi Sepuluh Nopember)

Leon Andretti Abdillah, S.Kom., M.M. (Universitas Bina Darma)

Radityo Prasetianto W, S.Kom., M.Kom. (Institut Teknologi Sepuluh Nopember) 
OAJIS Journal of

Information

Systems

is.its.ac.id/pubs/oajis/

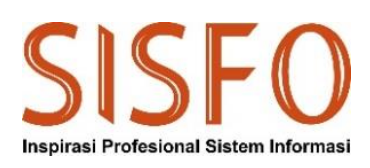

Jurnal Sisfo Vol. 08 No. 02 (2019) iii

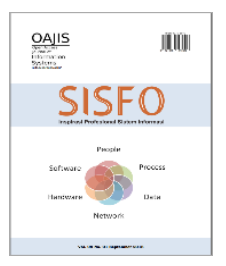

\section{Daftar Isi}

Evaluasi Kerangka Kerja Perencanaan Keberlangsungan Bisnis pada PT. Lotte Chemical Titan Nusantara

Mochammad Ikmal Amirullah, Apol Pribadi Subriadi......

ShopVis: Visualisasi Interaktif Persebaran Toko Daring di Indonesia Menggunakan Crowdsourced Data

Ruktin Handayani, Mohammad Arif Rasyidi. 99

Blended Learning dari Perspektif Para Guru Sekolah di Pondok Pesantren

Ahmad Muklason, Faizal Mahananto, Wiwik Anggraeni, Arif Djunaidy, Edwin Riksakomara .....

Pembuatan Prosedur dan Formulir Service Desk Pemerintahan Kota Madiun Berdasarkan ITIL V3

Zulaikah Effendi, Anisah Herdiyanti, Tony Dwi Susanto.

Rancang Bangun Dashboard dan Visualisasi Data Kickstarter dengan Pendekatan Business Intelligence

Irmasari Hafidz, Achmad Mirfak, Anisah Azhari, Aufar Ilham Adianto, Berry Humaidi Fuad, M. Ihsan Farabi .... 
Halaman ini sengaja dikosongkan 

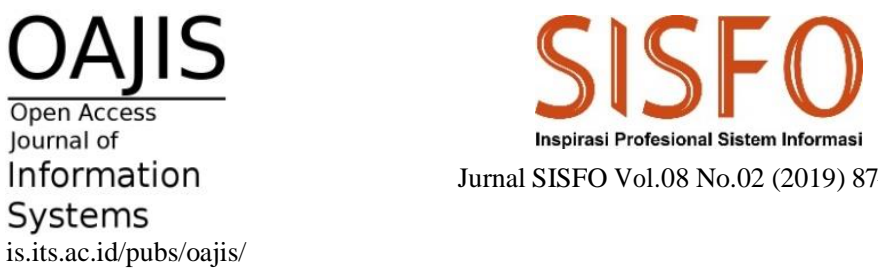

Jurnal SISFO Vol.08 No.02 (2019) 87-98

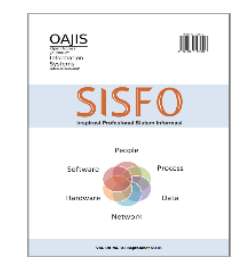

\title{
Evaluasi Kerangka Kerja Perencanaan Keberlangsungan Bisnis pada PT. Lotte Chemical Titan Nusantara
}

\author{
Mochammad Ikmal Amirullah, Apol Pribadi Subriadi* \\ Departemen Sistem Informasi, Fakultas Teknologi Informasi dan Komunikasi, Institut Teknologi Sepuluh Nopember
}

\begin{abstract}
Business Continuity Plan (BCP) is a company's plan to maintain its business continuity. When implementing BCP, a framework is needed to make the resulting $\mathrm{BCP}$ meet the needs of the company. One of the frameworks that can be used in BCP implementation is the BCP framework proposed by Yusrida. However, this framework can not be used as a standard because of the lack of empirical studies. The purpose of this research is to create BCP as well as to test the BCP framework proposed by Yusrida. This study was conducted with two scenarios. the first scenario is to implement BCP at PT. Lotte Chemical Titan Nusantara which follows the Yusrida's BCP framework and the second scenario is to evaluate each stage of the framework. The results of this study are recommendations for improvements to the framework based on findings from the implementation of the Yusrida BCP framework at PT. Lotte Chemical Titan Nusantara.
\end{abstract}

Keywords: Business Continuity Plan, BCP Implementation, BCP Framework Evaluation

\begin{abstract}
Abstrak
Perencanaan keberlangsungan bisnis atau business continuity plan (BCP) adalah sebuah rencana yang dilakukan perusahaan untuk mempertahankan keberlangsungan bisnisnya. Dalam melakukan implementasi BCP, diperlukan suatu kerangka kerja agar BCP yang dihasilkan bisa memenuhi kebutuhan perusahaan. Salah satu kerangka kerja yang dapat digunakan untuk implementasi BCP adalah kerangka kerja BCP yang diusulkan oleh Yusrida. Namun kerangka kerja ini belum bisa dijadikan sebagai standar karena kurangnya kajian empiris. Tujuan dari penelitian ini adalah membuat BCP sekaligus menguji kerangka kerja BCP Yusrida. Penelitian ini dilakukan dengan dua skenario. skenario pertama melakukan implementasi BCP pada PT. Lotte Chemical Titan Nusantara sesuai dengan kerangka kerja BCP Yusrida dan skenario kedua melakukan evaluasi setiap tahapan pada kerangka kerja apakah bisa dilakukan. Hasil dari penelitian ini berupa rekomendasi perbaikan terhadap kerangka kerja yang dikembangkan oleh Yusrida berdasarkan temuan dari hasil pelaksanaannya di PT. Lotte Chemical Titan Nusantara.
\end{abstract}

Kata kunci: Perencanaan Keberlangsungan Bisnis, Implementasi BCP, Evaluasi Kerangka Kerja BCP

(C) 2019 Jurnal SISFO.

Histori Artikel: Disubmit 26-08-2018; Direvisi 22-10-2018; Diterima 13-11-2018; Tersedia online 30-01-2019

${ }^{*}$ Corresponding Author

Email address: apolpribadi@ gmail.com (Apol Pribadi Subriadi)

https://doi.org/10.24089/j.sisfo.2019.01.001 


\section{Pendahuluan}

Perusahaan perlu melakukan perencanaan keberlangsungan bisnis atau Business Continuity Plan (BCP) sehingga proses bisnis yang mereka miliki dapat bertahan. BCP adalah sebuah rencana yang dilakukan perusahaan untuk mempertahankan keberlangsungan bisnisnya. BCP memiliki fokus utama terhadap: bagaimana menjamin kontinuitas dari bisnis ketika kehilangan akses terhadap manusia, fasilitas, sistem informasi, layanan dan sumber daya [1]. BCP dirancang untuk mengurangi dampak negatif dari gangguan bisnis yang disebabkan oleh internal dan eksternal [2]. Pembuatan Business Continuity Plan ini merupakan upaya untuk mencegah gangguan terhadap aktivitas bisnis normal [3].

Implementasi Business Continuity Plan (BCP) merupakan sesuatu yang unik sehingga tidak akan sama BCP yang dimiliki oleh satu perusahaan dengan perusahaan lainnya. Keunikan ini dikarenakan BCP yang dibuat oleh perusahaan disesuaikan dengan kebutuhan dan kondisi perusahaan [4]. Selain itu, kerangka BCP dapat terus berkembang mengikuti kesesuaian dengan perusahaan. Dari beberapa standar terkini mengenai BCP yaitu ISO 22301:2012, COBIT 5 Domian: Manage Continuity dan ITIL - IT Service Continuity Management, terdapat keterbatasan dari masing-masing standar yaitu belum mencakup secara detil mengenai alur dari Business Continuity Plan [5].

Sebuah usulan kerangka kerja BCP oleh [5] membahas mengenai alur dari BCP secara detil. Kerangka kerja ini bersifat general yang artinya dapat diimplementasikan pada segala jenis perusahaan terlepas dari ukuran, aktivitas atau sektornya [5]. Kerangka kerja ini terdiri dari 4 fase mengikuti siklus PDCA pada ISO yaitu Plan, Do, Check, dan Action. Namun kajian empiris pada kerangka kerja tersebut masih kurang sehingga perlu adanya kajian empiris lain untuk menunjukan bahwa kerangka kerja ini dapat diimplementasikan pada perusahaan apapun.

PT. Lotte Chemical Titan Nusantara merupakan salah satu perusahaan besar yang bergerak dibidang produksi polyethylene. Perusahaan ini telah menerapkan teknologi informasi untuk membantu dalam menjalankan proses bisnisnya. Namun penerapan tersebut dapat menimbulkan berbagai macam risiko yang dapat mengganggu proses bisnis mereka. Perusahaan memerlukan BCP untuk menjamin agar perusahaan dapat menghadapi risiko-risiko yang muncul dan menjaga kontinuitas dari bisnis yang mereka miliki.

Berangkat dari permasalahan tersebut, penelitian ini bertujuan untuk membuat BCP sekaligus menguji kerangka kerja BCP Yusrida. Dalam mencapai tujuan tersebut dilakukan dengan dua skenario. skenario pertama melakukan implementasi BCP pada PT. Lotte Chemical Titan Nusantara sesuai dengan kerangka kerja BCP Yusrida dan skenario kedua melakukan evaluasi setiap tahapan pada kerangka kerja apakah bisa dilakukan.

\section{Tinjauan Pustaka/Penelitian Sebelumnya}

Berikut merupakan tinjauan pustaka terhadap beberapa teori yang dijadikan acuan atau landasan dalam penelitian ini.

\subsection{Business Continuity Plan}

Business Continuity Plan (BCP) merupakan suatu kerangka kerja yang digunakan untuk membuat dan memvalidasi rencana untuk mempertahankan operasi bisnis secara terus menerus, sebelum, selama dan setelah bencana dan insiden yang mengganggu [6]. BCP didefinisikan sebagai dokumen berisi prosedur yang bertujuan untuk menjadi panduan perusahaan dalam merespon, melindungi, melanjutkan dan mengembalikan (respond, recover, resume, restore) proses bisnis perusahaan ke level yang telah didefinisikan sebelumnya setelah terjadi gangguan [7]. Business Continuity Plan berhubungan dengan mengidentifikasi, memperoleh, mengembangkan, mendokumentasikan serta menguji sumber daya dan 
prosedur sehingga proses bisnis kritir suatu organisasi dapat terjaga saat terjadi bencana atau insiden apapun [8].

\subsection{Kerangka Kerja BCP Yusrida}

Kerangka kerja BCP Yusrida adalah salah satu kerangka kerja BCP yang menjelaskan secara teknis mengenai alur dalam membuat rencana keberlangsungan bisnis. Kerangka kerja ini bersifat general yang artinya dapat diimplementasikan pada segala jenis perusahaan terlepas dari ukuran, aktivitas atau sektornya [5]. Fokus dari kerangka kerja ini yaitu manajemen risiko serta fungsi bisnis yang menerapkan teknologi informasi. Kerangka kerja mengadopsi siklus PDCA (Plan-Do-Check-Act) yang umum diterapkan oleh ISO [5]. Gambar 1 merupakan ilustrasi dari kerangka kerja BCP Yusrida yang pada setiap siklusnya berisikan elemen utama dari BCP [5].

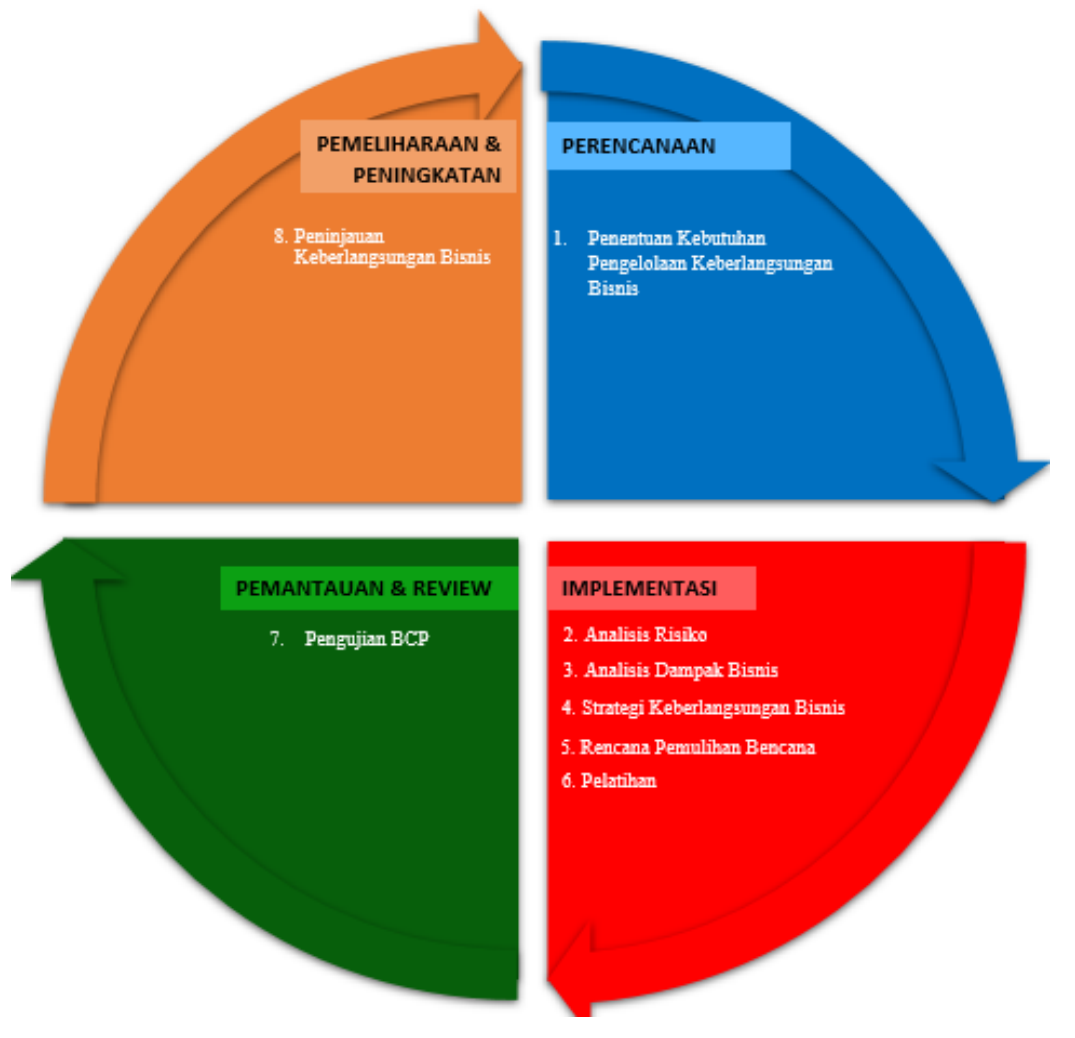

Gambar 1. Metodologi BCP Yusrida

Fase pertama pada kerangka kerja Yusrida dipaparkan pada Gambar 3 fokus pada pendetilan kebutuhan awal dalam lingkup manajemen terkait dengan tujuan, ruang lingkup, peran manajemen, sumber daya dan komunikasi [5]. Pada fase ini terdapat elemen penentuan kebutuhan pengelolaan keberlangsungan bisnis. Aktivitas yang meliputi elemen ini sebagai berikut [5]:

1) Menentukan tujuan dari adanya perencanaan keberlangsungan bisnis pada perusahaan.

2) Menentukan ruang lingkup yang akan menjadi bagian dari perencanaan keberlangsungan bisnis.

3) Melakukan pembentukan komite BCP, komite BCP ini yang akan bertanggungjawab mengenai perencanaan keberlangsungan bisnis perusahaan.

4) Menentukan peran dan tanggung jawab dari komite BCP

5) Menentukan pihak internal atau eksternal yang berkaitan dengan kelangsungan bisnis perusahaan 
6) Menentukan sumber daya baik manusia maupun perangkat untuk dapat memastikan bahwa proses berjalan dengan lancar dan sesuai dengan perencanaan.

7) Membuat alur komunikasi saat terjadi gangguan dalam perusahaan beserta dengan kontak dari pihak yang akan dihubungi

Fase kedua pada kerangka kerja Yusrida dipaparkan pada Gambar 4. Pada fase ini terdapat beberapa elemen yang perlu dilalui yaitu [5]:

1) Analisis Risiko

Eelemen ini fokus pada identifikasi kemungkinan risiko apa saja yang dimiliki oleh perusahaan, penilaian risiko dan dampak dari risiko. Aktivitas pada elemen ini meliputi.

a. Melakukan pendataan risiko yang mungkin diterima oleh perusahaan berdasarkan komponen TI.

b. Melakukan analisis dari setiap risiko untuk mengetahui penyebab.

c. Memberikan nilai pada setiap risiko berdasarkan tingkat kemungkinan terjadi risiko, tingkat dampak dan deteksi yang dimiliki perusahaan.

2) Analisis Dampak Bisnis

Pada elemen ini berfokus pada identifikasi dan prioritasi fungsi bisnis beserta dengan aset, penentuan jangka waktu toleransi gangguan, dan identifikasi dampak dari adanya gangguan. Aktivitas pada elemen ini meliputi.

a. Melakukan pendataan proses bisnis perusahaan beserta layanan TI yang mendukung.

b. Melakukan prioritasi dari layanan TI sesuai dengan tingkat kritis

c. Melakukan prioritasi proses bisnis perusahaan sesuai dengan tingkat kritis

d. Melakukan analisis dampak dari adanya gangguan berdasarkan aspek finansialm reputasi dan teknis.

e. Menentukan waktu pemulihan pada tiap layanan TI

3) Penyusunan Strategi Keberlangsungan Bisnis

Pada elemen ini berfokus pada penentuan pertanggungjawaban atas dampak gangguan yang mengganggu proses bisnis dan pengembangan prosedur pengelolaan kerusakan atau gangguan. Aktivitas pada elemen ini meliputi.

a. Menentukan strategi preventif atau pencegahan untuk mengurangi risiko dan dampak.

b. Menentukan strategi mengenai tindakan atau aksi yang harus dilakukan oleh tim DRP agar dapat mengatasi gangguan dan melakukan pemulihan.

c. Menentukan strategi dalam mengatasi gangguan dan mengembalikan proses bisnis agar dapat kembali berjalan dalam kondisi normal, strategi ini dilakukan oleh seluruh pihak yang terkait dalam BCP.

d. Melakukan koreksi terhadap strategi yang telah dibuat, apabila terdapat ketidaksesuaian atau kurang efektif

4) Rencana Pemulihan Bencana

Pada elemen ini berfokus pada penanganan insiden, prosedur saat bencana beserta detil mengenai pihak yang bersangkutan dan pemulihan bencana. Aktivitas pada elemen ini meliputi.

a. Melakukan pendataan aset TI yang dimiliki perusahaan.

b. Melakukan pendataan vendor jasa atau produk yang dibutuhkan beserta dengan tanggungjawabnya.

c. Menentukan lokasi server atau aset TI yang aman terhadap bencana

d. Membuat bentuk kontrol dari bencana atau gangguan.

e. Menentukan bilamana akan dilakukan aktivasi pemulihan mulai dari deklarasi status sampai kepada de-aktivasi.

f. Membuat skenario pengujian dan melakukan simulasi pengujian. 
g. Melakukan evaluasi hasil pengujian dan melakukan revisi bentuk kontrol dari rencana pemulihan bencana

5) Pelatihan Karyawan

Pada elemen ini berfokus pada proses pelatihan yang mencakup mekanisme penyampaian pelatihan, pelaksanaan pelatihan yang terdiri dari latihan dan ujian, dan pemantauan kompetensi berdasarkan hasil latihan dan ujian. Aktivitas pada elemen ini meliputi.

a. Menentukan jenis pelatihan yang sesuai dengan kebutuhan perusahaan.

b. Menentukan mekanisme penyampaian pelatihan

c. Merancang dan memenuhi sumber daya yang diperlukan dalam melaksanakan pelatihan.

d. Melaksanakan pelatihan sesuai dengan mekanisme yang telah ditentukan

\section{Metodologi}

Pada Gambar 2 dijelaskan mengenai tahapan atau metodologi pengerjaan penelitian ini. Terdapat 4 tahapan yang perlu dilakukan yaitu a) penggalian data; b) pelaksanaan kerangka kerja BCP; c) analisis hasil pelaksanaan; dan d) rekomendasi perbaikan kerangka kerja. Penggalian data pada penelitian ini dilakukan dengan teknik wawancara kepada pihak yang bertanggung jawab atas pengelolaan teknologi informasi dan analisis dokumen perusahaan. Selanjutnya pelaksanaan kerangka kerja BCP dilakukan dengan mengikuti 4 fase pada kerangka kerja BCP Yusrida, yaitu c.1) fase perencanaan yang terdiri dari elemen penentuan pengelolaan keberlangsungan bisnis; c.2) fase implementasi yang terdiri dari elemen analisis risiko, analisis dampak bisnis, strategi keberlangsungan bisnis, rencana pemulihan bencana, dan pelatihan karyawan; c.3) fase pemantauan dan review yang terdiri dari elemen pengujian BCP; dan c.4) fase peningkatan dan pemeliharaan dimana pada fase tersebut terdiri dari elemen peninjauan keberlangsungan bisnis. Selanjutnya dilakukan analis hasil pelaksanaan kerangka kerja BCP Yusrida yang telah dilakukan. Setelah dilakukan analisis dari hasil pelaksanaan maka bisa didapatkan rekomendasi untuk perbaikan dari kerangka kerja Yusrida.

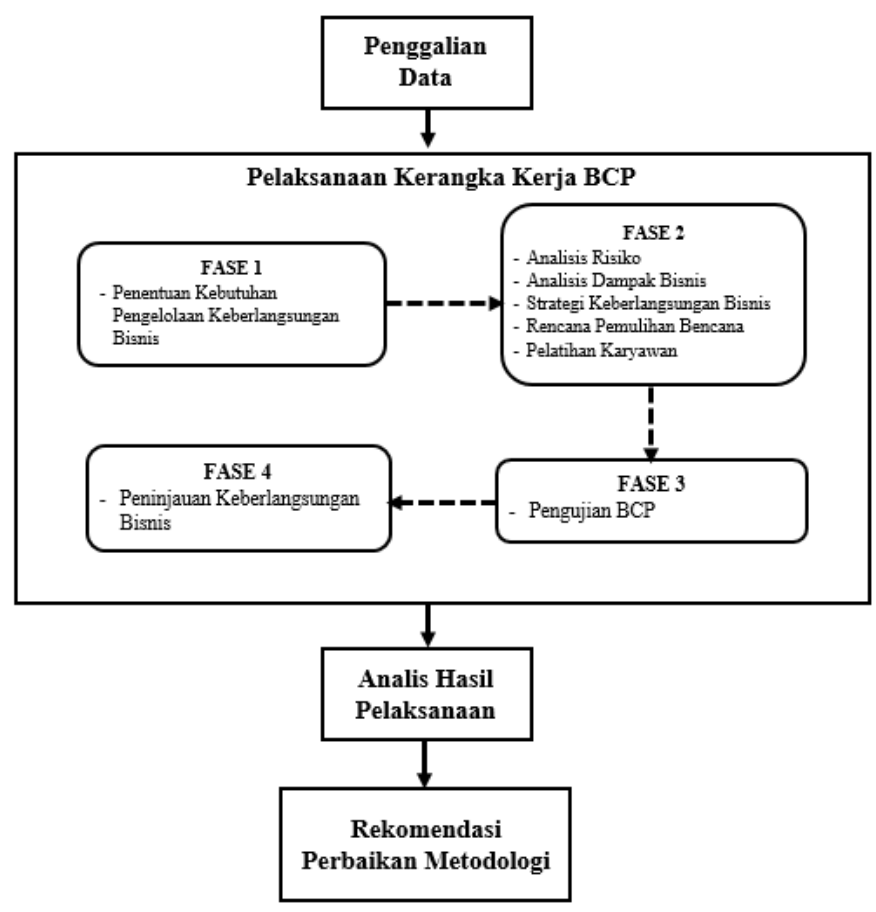

Gambar 2. Tahap metodologi penelitian 


\section{Hasil dan Pembahasan}

Bagian ini menjelaskan mengenai hasil yang didapatkan dari penelitian yang telah dilakukan. Hasil yang dibahas difokuskan pada 3 paparan, yaitu: 1) pelaksanaan kerangka kerja BCP Yusrida; 2) analisis hasil pelaksanaan; dan 3) rekomendasi perbaikan kerangka kerja.

\subsection{Pelaksanaan Kerangka kerja BCP}

Pelaksanaan kerangka kerja BCP dilakukan mengikuti 4 fase kerangka kerja BCP Yusrida yaitu, a) fase perencanaan; b) fase implementasi; c) fase pemantauan dan review; dan d) fase pemeliharaan dan peningkatan. Keseluruhan dari pelaksanaan kerangka kerja BCP Yusrida menghasilkan dokumen BCP PT. Lotte Chemical Titan Nusantara yang terdiri dari beberapa bagian. Pada fase perencanaan, bagian yang dihasilkan yaitu a.1) halaman kontrol dokumen; a.2) tujuan; a.3) ruang lingkup; a.4) struktur dan peran manajemen; a.5) sumber daya pendukung; a.6) alur komunikasi; dan a.7) daftar kontak darurat. Selanjutnya pada fase implementasi, bagian yang dihasilkan yaitu b.1) daftar aset kritis, b.2) analisa risiko, b.3) daftar layanan TI; b.4) prioritas proses bisnis dan layanan TI; b.5) waktu pemulihan bencana; b.6) strategi keberlangsungan bisnis; b.7) daftar vendor; b.8) kriteria lokasi server, aktivasi, dan deaktivasi; b.9) bentuk kontrol, b.10) mekanisme pelatihan; dan b.11) modul pelatihan. Selanjutnya pada fase pemantauan dan review bagian yang dihasilkan yaitu c.1) skenario pengujian; dan c.2) hasil pengujian. Terakhir pada fase pemeliharaan dan peningkatan, bagian yang dihasilkan yaitu d.1) periode waktu peninjauan; dan d.2) perangkat peninjauan keberlangsungan bisnis

\subsection{Analisis Hasil Pelaksanaan}

Analisis hasil pelaksanaan dilakukan dengan mengacu pada bagian yang dihasilkan dari dokumen BCP dengan kesesuaian keterangan pada kerangka kerja BCP Yusrida. Pada kerangka kerja BCP Yusrida terdapat 4 fase, 8 kegiatan, dan 38 aktivitas yang harus dilakukan. Akan tetapi terdapat beberapa aktivitas yang tidak dilakukan atau berbeda dengan keterangan pada kerangka kerja BCP karena penyesuaian dengan data yang didapatkan.

Tabel 1. Detail analisis hasil pelaksanaan

\begin{tabular}{|c|c|c|c|}
\hline Elemen & Aktivitas & Status & Keterangan \\
\hline \multicolumn{4}{|c|}{ FASE 1 : PERENCANAAN } \\
\hline \multirow{7}{*}{$\begin{array}{l}\text { Penentuan kebutuhan } \\
\text { pengelolaan } \\
\text { keberlangsungan } \\
\text { bisnis }\end{array}$} & Penentuan tujuan & Dilakukan & Menghasilkan bagian tujuan \\
\hline & Penentuan ruang lingkup & Dilakukan & Menghasilkan bagian ruang lingkup \\
\hline & Pembentukan komite & Dilakukan & Menghasilkan bagian struktur dan \\
\hline & Penentuan tanggung jawab komite & Dilakukan & peran manajemen \\
\hline & Penentuan pihak terkait & $\begin{array}{l}\text { Terdapat } \\
\text { perubahan }\end{array}$ & $\begin{array}{l}\text { Pihak internal terdapat pada bagian } \\
\text { bagian struktur dan peran manajemen } \\
\text { dan pihak eksternal terdapat pada } \\
\text { bagian daftar vendor }\end{array}$ \\
\hline & Penentuan sumber daya & Dilakukan & $\begin{array}{l}\text { Menghasilkan bagian sumber daya } \\
\text { pendukung }\end{array}$ \\
\hline & Pembuatan alur komunikasi & Dilakukan & $\begin{array}{l}\text { Menghasilkan bagian } \\
\text { komunikasi, dan daftar kontak } \\
\text { darurat }\end{array}$ \\
\hline \multicolumn{4}{|c|}{ FASE 2 : IMPLEMENTASI } \\
\hline \multirow[t]{3}{*}{ Analisis risiko } & Pendataan kemungkinan risiko & $\begin{array}{l}\text { Terdapat } \\
\text { perubahan }\end{array}$ & $\begin{array}{l}\text { Perubahan terjadi karena risiko } \\
\text { berdasarkan aset TI. Hasil dari }\end{array}$ \\
\hline & Analisis risiko & $\begin{array}{l}\text { Terdapat } \\
\text { perubahan }\end{array}$ & $\begin{array}{l}\text { aktivitas ini yaitu bagian daftar aset } \\
\text { kritis dan analisis risiko }\end{array}$ \\
\hline & Penilaian risiko & Dilakukan & Menghasilkan bagian analisis risiko \\
\hline $\begin{array}{l}\text { Analisis } \\
\text { bisnis }\end{array}$ & $\begin{array}{l}\text { Pendataan proses bisnis dan } \\
\text { Layanan TI }\end{array}$ & Dilakukan & $\begin{array}{l}\text { Menghasilkan bagian daftar layanan } \\
\text { TI }\end{array}$ \\
\hline
\end{tabular}




\begin{tabular}{|c|c|c|c|}
\hline Elemen & Aktivitas & Status & Keterangan \\
\hline & Prioritasi layanan TI & $\begin{array}{l}\text { Terdapat } \\
\text { perubahan }\end{array}$ & $\begin{array}{l}\text { Dilakukan perubahan dalam } \\
\text { menentukan prioritas layanan TI dan }\end{array}$ \\
\hline & Prioritasi proses bisnis & $\begin{array}{l}\text { Terdapat } \\
\text { perubahan }\end{array}$ & $\begin{array}{l}\text { proses bisnis karena penentuan } \\
\text { berdasarkan dampak gangguan. } \\
\text { Aktivitas ini menghasilkan bagian } \\
\text { prioritas proses bisnis dan layanan TI }\end{array}$ \\
\hline & Analisis dampak gangguan & $\begin{array}{l}\text { Terdapat } \\
\text { perubahan }\end{array}$ & $\begin{array}{l}\text { Analisis dampak gangguan dilakukan } \\
\text { terlebih dahulu sebelum prioritasi. } \\
\text { Aktivitas ini menghasilkan bagian } \\
\text { prioritas proses bisnis dan layanan TI }\end{array}$ \\
\hline & Penentuan waktu pemulihan & Dilakukan & $\begin{array}{l}\text { Menghasilkan bagian waktu } \\
\text { pemulihan bencana }\end{array}$ \\
\hline \multirow{4}{*}{$\begin{array}{l}\text { Strategi } \\
\text { keberlangsungan } \\
\text { bisnis }\end{array}$} & Penentuan strategi preventif & Dilakukan & Semua strategi disatukan sehingga \\
\hline & Penentuan strategi saat gangguan & Dilakukan & menghasilkan bagian strategi \\
\hline & Penentuan strategi pemulihan & Dilakukan & keberlangsungan bisnis \\
\hline & Koreksi terhadap strategi & $\begin{array}{l}\text { Terdapat } \\
\text { perubahan }\end{array}$ & $\begin{array}{l}\text { Perubahan yang terjadi yaitu } \\
\text { dijadikan sebuah strategi korektif dan } \\
\text { disatukan pada bagian strategi } \\
\text { keberlangsungan bisnis. }\end{array}$ \\
\hline \multirow[t]{7}{*}{$\begin{array}{l}\text { Rencana } \\
\text { bencana }\end{array}$} & Pendataan aset TI & $\begin{array}{l}\text { Terdapat } \\
\text { perubahan }\end{array}$ & $\begin{array}{l}\text { Aktivitas sudah dilakukan karena } \\
\text { menggunakan metodologi OCTAVE }\end{array}$ \\
\hline & Pendataan vendor & Dilakukan & Menghasilkan bagian daftar vendor \\
\hline & Penentuan lokasi server dan aset TI & Dilakukan & $\begin{array}{l}\text { Menghasilkan bagian kriteria lokasi } \\
\text { server, aktivasi, dan deaktivasi }\end{array}$ \\
\hline & Pembuatan kontrol & Dilakukan & Menghasilkan bagian bentuk kontrol \\
\hline & Penentuan aktivasi \& deaktivasi & Dilakukan & $\begin{array}{l}\text { Menghasilkan bagian kriteria lokasi } \\
\text { server, aktivasi, dan deaktivasi }\end{array}$ \\
\hline & Skenario pengujian & $\begin{array}{l}\text { Terdapat } \\
\text { perubahan }\end{array}$ & $\begin{array}{l}\text { Perubahan terjadi karena aktivitas ini } \\
\text { dilakukan pada elemen pengujian } \\
\text { BCP. }\end{array}$ \\
\hline & Evaluasi bentuk kontrol & $\begin{array}{l}\text { Tidak } \\
\text { dilakukan }\end{array}$ & $\begin{array}{l}\text { Evaluasi tidak dijelaskan pada } \\
\text { penelitian ini karena kegiatan } \\
\text { evaluasi baru bisa dilakukan apabila } \\
\text { BCP telah dijalankan dan pihak } \\
\text { manajemen belum } \\
\text { melakukannya }\end{array}$ \\
\hline \multirow[t]{4}{*}{ Pelatihan karyawan } & Penentuan jenis pelatihan & $\begin{array}{l}\text { Terdapat } \\
\text { perubahan }\end{array}$ & $\begin{array}{l}\text { Perubahan dikarenakan aktivitas ini } \\
\text { dibahas pada bagian modul pelatihan }\end{array}$ \\
\hline & Mekanisme penyampaian pelatihan & Dilakukan & $\begin{array}{l}\text { Menghasilkan bagian mekanisme } \\
\text { pelatihan }\end{array}$ \\
\hline & Rencana kebutuhan pelatihan & $\begin{array}{l}\text { Terdapat } \\
\text { perubahan }\end{array}$ & $\begin{array}{l}\text { Perubahan dikarenakan aktivitas ini } \\
\text { dibahas pada bagian modul pelatihan }\end{array}$ \\
\hline & Pelaksanaan pelatihan & $\begin{array}{l}\text { Tidak } \\
\text { dilakukan }\end{array}$ & $\begin{array}{l}\text { Pelatihan tidak dijelaskan pada } \\
\text { penelitian ini karena kegiatan } \\
\text { pelatihan baru bisa dilakukan apabila } \\
\text { BCP telah jalankan dan perusahaan } \\
\text { belum bisa melakukan pelatihan. }\end{array}$ \\
\hline \multicolumn{4}{|c|}{ FASE 3 : PEMANTAUAN \& REVIEW } \\
\hline \multirow[t]{4}{*}{ Pengujian BCP } & Perencanaan mekanisme pengujian & $\begin{array}{l}\text { Terdapat } \\
\text { perubahan }\end{array}$ & $\begin{array}{l}\text { Perubahan yang terjadi yaitu } \\
\text { dijadikan bagian skenario pengujian }\end{array}$ \\
\hline & Pengujian & Dilakukan & Menghasilkan bagian hasil pengujian \\
\hline & Pencatatan pengujian & Dilakukan & \\
\hline & Dokumentasi hasil pengujian & Dilakukan & \\
\hline \multicolumn{4}{|c|}{ FASE 4 : PEMELIHARAAN \& PENINGKATAN } \\
\hline $\begin{array}{l}\text { Peninjauan } \\
\text { keberlangsungan }\end{array}$ & $\begin{array}{l}\text { Penentuan } \\
\text { peninjauan }\end{array}$ & Dilakukan & $\begin{array}{l}\text { Menghasilkan bagian periode waktu } \\
\text { peninjauan }\end{array}$ \\
\hline
\end{tabular}




\begin{tabular}{llll}
\hline \multicolumn{1}{c}{ Elemen } & \multicolumn{1}{c}{ Aktivitas } & \multicolumn{1}{c}{ Status } & \multicolumn{1}{c}{ Keterangan } \\
\hline bisnis & Peninjauan secara berkala & Tidak & Evaluasi tidak dijelaskan pada \\
& dilakukan & penelitian ini karena kegiatan \\
& Pengkajian ulang terhadap rencana & Tidak & evaluasi baru bisa dilakukan apabila \\
& & dilakukan & BCP telah jalankan dan pihak \\
& Pertimbangan terhadap perubahan & Tidak & manajemen belum bisa \\
& & dilakukan & melakukannya. Penjelasan hanya \\
& & mengenai perangkat yang membantu \\
& & dalam melakukan peninjauan. \\
\hline
\end{tabular}

Tabel 1 menjelaskan detail dari kesesuaian hasil pelaksanaan kerangka kerja BCP dengan kerangka kerja BCP Yusrida. Kolom status berisi penjelasan tentang kesimpulan dari aktivitas pada kerangka kerja apakah dilakukan atau tidak dilakukan, atau terdapat perubahan. Status dilakukan menandakan bahwa aktivitas tersebut dilakukan ketika pelaksanaan kerangka kerja dan memiliki hasil pada dokumen BCP. Status tidak dilakukan menandakan bahwa aktivitas tersebut tidak dilakukan karena keterbatasan penelitian dan pihak manajemen belum bisa melakukannya. Status terdapat perubahan menandakan bahwa aktivitas tersebut dilakukan tetapi dengan perubahan sehingga tidak sesuai dengan kerangka kerja. Perubahan ini terjadi untuk menyesuaikan dengan data yang didapat pada penelitian ini.

\subsection{Rekomendasi Perbaikan Kerangka kerja}

Rekomendasi perbaikan kerangka kerja didapatkan berdasarkan temuan analisis hasil pelaksanaan kerangka kerja BCP Yusrida. Rekomendasi yang diberikan bertujuan agar kerangka kerja BCP Yusrida bisa diimpelentasikan pada perusahaan yang berbeda karena setiap implementasi BCP harus disesuaikan dengan kebutuhan perusahaan. Rekomendasi perbaikan ditandai dengan tanda bintang (*) pada aktivitas di kerangka kerja sehingga menandakan adanya perubahan pada aktivitas tersebut. Pada fase pertama sebagaimana pada Gambar 3 rekomendasi yang diberikan yaitu menghilangkan aktivitas penentuan pihak terkait.

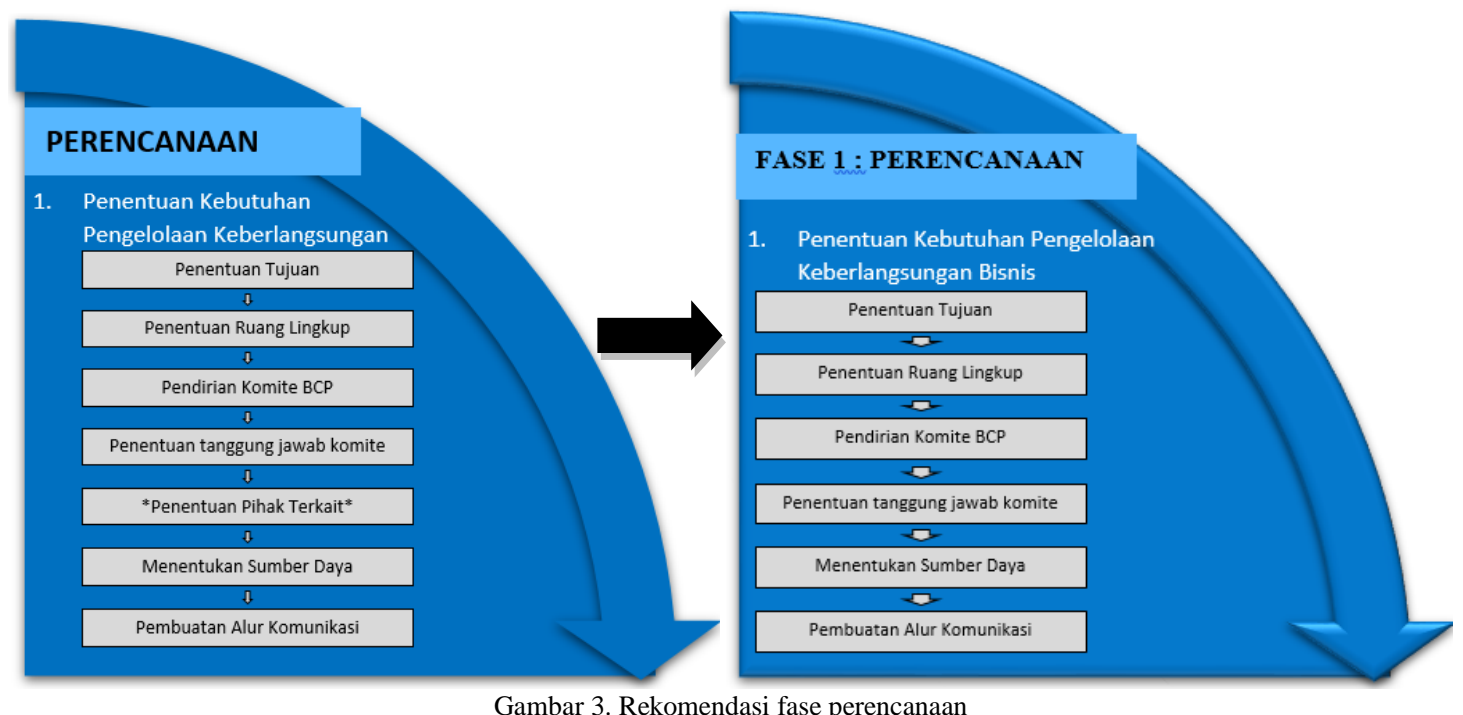

Selanjutnya sebagaimana pada Gambar 4 pada fase kedua rekomendasi yang diberikan terdapat pada beberapa elemen. Pada elemen analisis risiko aktivitas analisa risiko diubah menjadi pendataan aset TI karena risiko yang diberikan berdasarkan aset TI. Pada elemen analisis dampak bisnis analis dampak gangguan dilakukan terlebih dahulu sebagai landasan untuk menentukan prioritasi proses bisnis dan 
layanan TI. Pada elemen strategi keberlangsungan bisnis aktivitas koreksi terhadap strategi diubah menjadi penentuan strategi korektif. Pada elemen rencana pemulihan bencana terdapat aktivitas yang dihilangkan yaitu pendataan aset TI, pembuatan skenario pengujian, dan evaluasi bentuk kontrol. Pada elemen pelatihan karyawan aktivitas penentuan jenis pelatihan dan rencana kebutuhan pelatihan diubah menjadi pembuatan modul pelatihan.

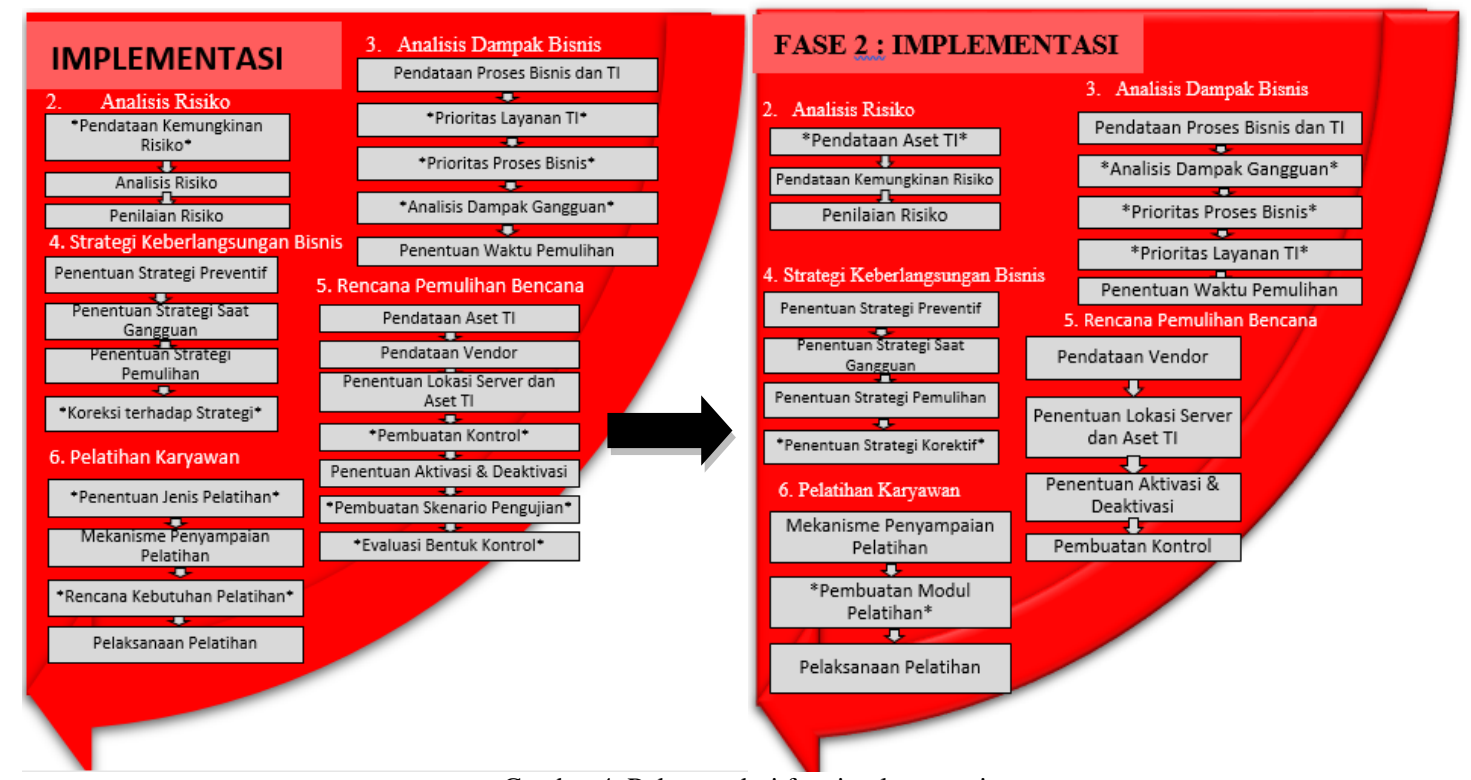

Gambar 4. Rekomendasi fase implementasi

Sebagaimana pada Gambar 5 pada fase ketiga rekomendasi yang diberikan terdapat pada elemen pengujian BCP. Aktivitas perencanaan mekanisme pengujian diubah menjadi pembuatan skenario pengujian.

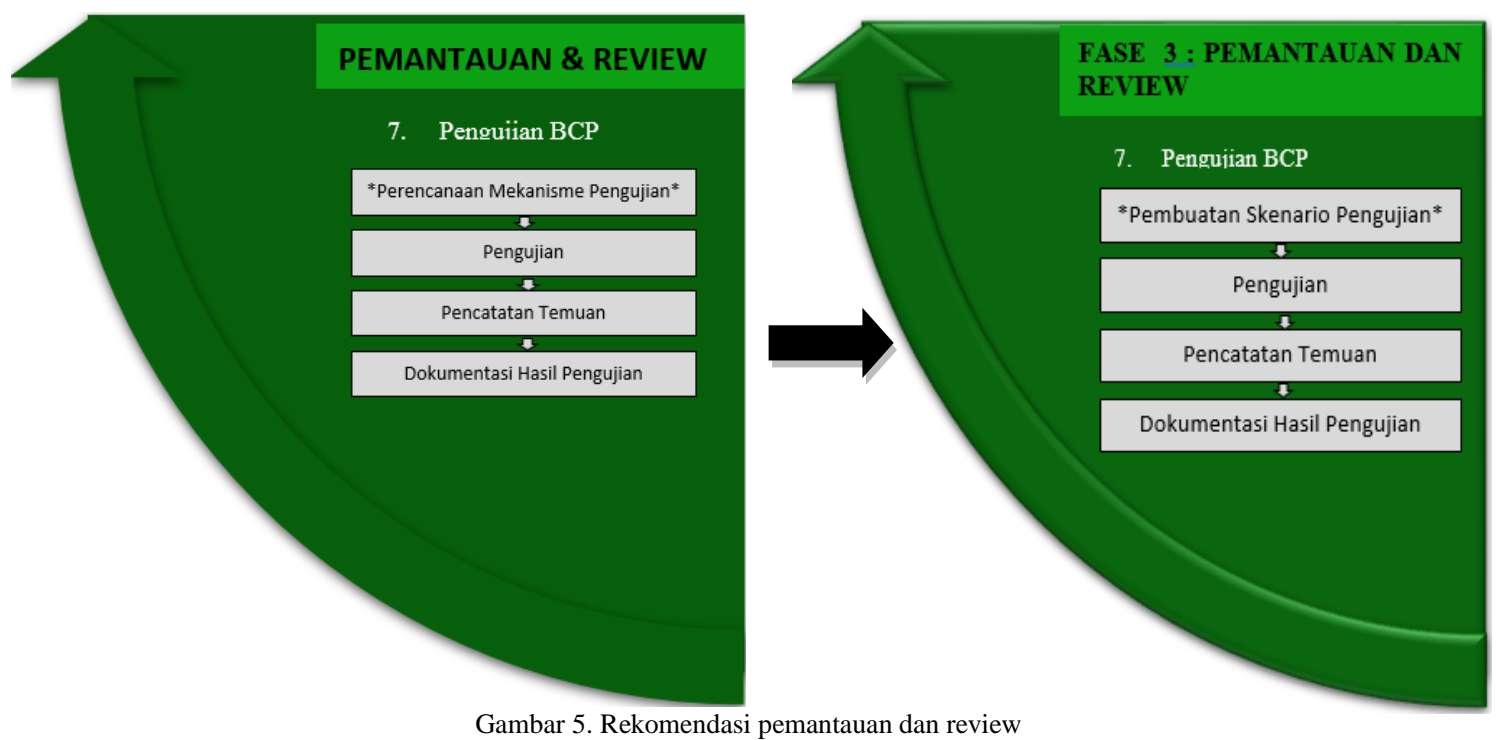

Selanjutnya pada fase terakhir sebagaimana pada Gambar 6 rekomendasi yang diberikan terdapat pada elemen peninjauan keberlangsungan bisnis. Terdapat tambahan aktivitas yaitu pembuatan perangkat peninjauan yang diakukan sebelum aktivitas peninjauan secara berkala. 


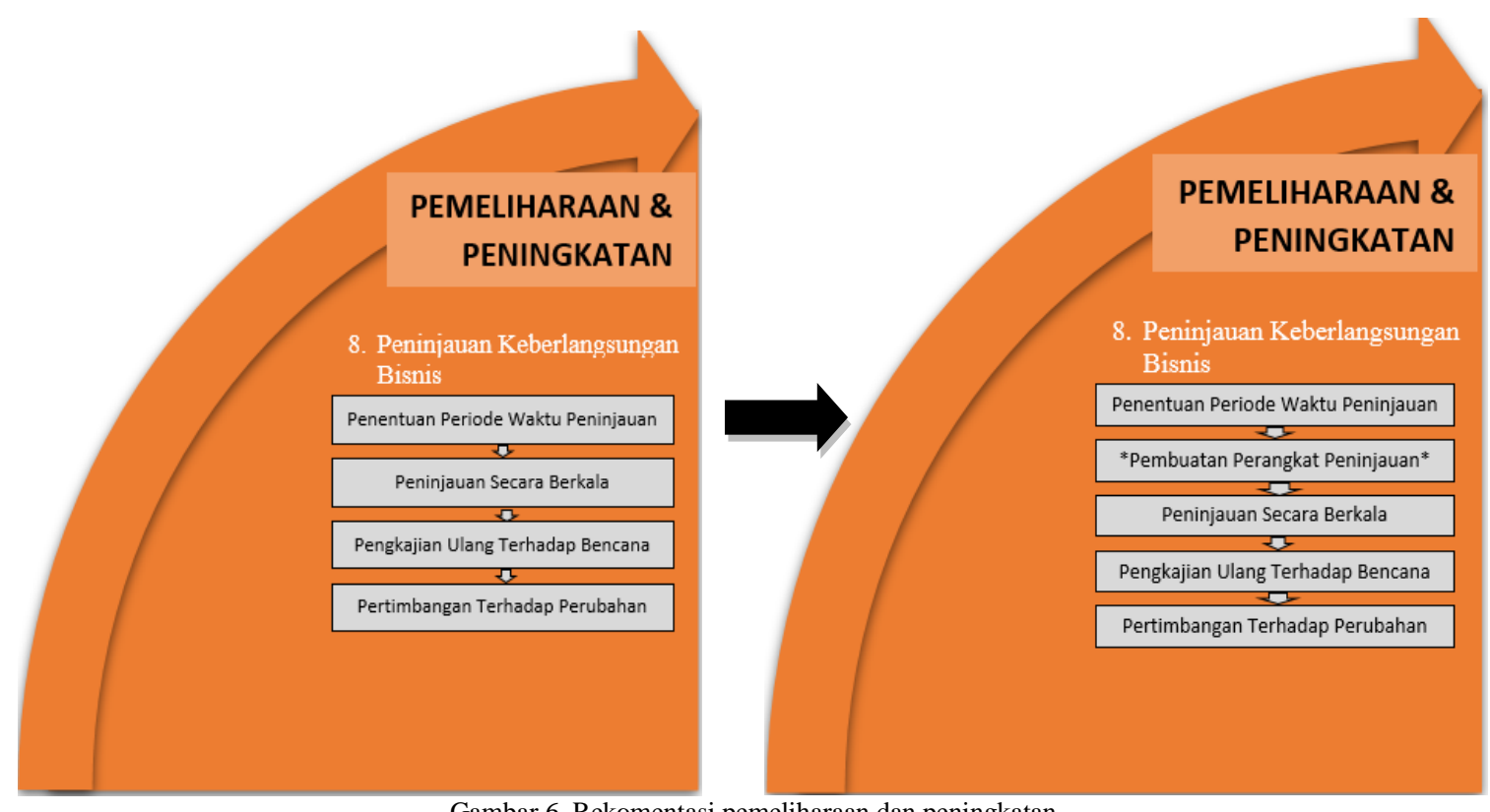

Gambar 6. Rekomentasi pemeliharaan dan peningkatan

\section{Kesimpulan}

Bagian ini berisi kesimpulan dari serangkaian proses penelitian dengan studi empiris PT. Lotte Chemical Titan Nusantara. Selain itu terdapat saran yang diberikan untuk penelitian dimasa yang akan datang.

\subsection{Simpulan}

Berdasarkan analisis hasil pelaksanaan kerangka kerja BCP Yusrida, dari 38 aktivitas yang diusulkan pada kerangka kerja tersebut terdapat 21 aktivitas yang dilakukan, 12 aktivitas yang terdapat perubahan, dan 5 aktivitas yang tidak dilakukan. Aktivitas yang terdapat perubahan terjadi karena penyesuaian dengan data yang didapatkan. Selanjutnya aktivitas yang tidak dilakukan terjadi karena aktivitas tersebut baru bisa dilakukan apabila BCP telah jalankan dan pihak manajemen belum bisa melakukannya.

Analisis hasil pelaksanaan kerangka kerja BCP Yusrida menjadi masukan untuk memberikan rekomendasi perbaikan. Dari hasil rekomendasi perbaikan didapatkan usulan kerangka kerja baru yang terdiri dari 4 fase, 8 elemen dan, 33 aktivitas. Usulan tersebut memiliki aktivitas yang lebih sedikit dari kerangka kerja BCP Yusrida karena terdapat beberapa aktivitas yang berubah dan tidak dilakukan selama proses pelaksanaan kerangka kerja BCP.

Terdapat dua keterbatasan dalam penelitian ini yang mempengaruhi hasil dari pelaksanaan kerangka kerja dan rekomendasi perbaikan. Keterbatasan yang pertama yaitu penelitian menggunakan kerangka kerja BCP Yusrida baru dilakukan pada penelitian ini sehingga referensi pelaksanaan kerangka kerja hanya didapatkan dari penelitian yang dilakukan oleh Yusrida. Keterbatasan yang kedua yaitu dalam pelaksanaan kerangka kerja BCP Yusrida kegiatan evaluasi dan pelatihan tidak dilakukan karena pihak manajemen dari PT. Lotte Chemical Titan Nusantara belum bisa melakukannya.

Secara keseluruhan, dapat dikatakan bahwa kerangka kerja BCP Yusrida bisa menjadi standar dalam melakukan perencanaan keberlangsungan bisnis di suatu perusahaan karena pada kerangka kerja tersebut dijelaskan alur BCP secara detil. 


\subsection{Saran}

Saran yang bisa diberikan dari penelitian ini untuk penelitian selanjutnya yaitu:

1) Dokumen BCP yang dihasilkan dari penelitian ini perlu dilakukan peninjauan secara berkala sehingga bisa menjamin keefektifan dan keakuratan dari BCP.

2) Usulan baru kerangka kerja BCP dari hasil rekomendasi pada penelitian ini bisa dijadikan acuan apabila terdapat penelitian selanjutnya yang menggunakan kerangka kerja BCP Yusrida.

3) Perlu adanya implementasi lain mengenai kerangka kerja ini sehingga kerangka kerja ini bisa dievaluasi untuk disempurnakan.

\section{Daftar Rujukan}

[1] S. Snedaker, Business Continuity and Disaster Recovery for IT Professionals, 2nd Edition, Elsevier Inc, 2014. [E-book] Available: Sciencedirect.

[2] A. Asgary and A. S. Naini, "Modelling the Adaptation of Business Continuity Planning by Businesses Using Neural Networks," Intelligent System in Accounting, Finance and Management, vol 18, p. 89-104, August 2011. Available: Doi, https://doi.org/10.1002/isaf.326. [Accessed August 12, 2018].

[3] U. Solehudin, Business Continuity and Disaster Recovery, IKI-83408T MTI U, [online document], 2005. Available: gunadarma, http://ftp.gunadarma.ac.id [Accessed: August 12, 2018].

[4] G. P. Pertiwi, "Kerangka Kerja Business Continuity Plan (BCP) Pada Teknologi Informasi Perusahaan Studi Kasus: PDAM Kota Surabaya," Sepuluh Nopember Institute of Technology, Surabaya, 2016.

[5] Y. Muflihah, "Business Continuity Plan: Sebuah Usulan Metodologi, Empiris PT. PLN (Persero) Distribusi Jawa Timur," Sepuluh Nopember Institute of Technology, Surabaya, 2017.

[6] ISO/TC 292, "ISO 22301 Societal Security-Business Continuity Management Systems-Requirements," International Organization for Standardization, Sweden, 2012.

[7] P. Ranjan and P. Kumar and K. Abhishek, "Business Continuity Planning in Indian Perspective," Journal of Advances in Computational Research: An International Journal, vol. 1, p. 7-13, January 2012. Available: researchgate, https://www.researchgate.net/publication/. [Accessed August 12, 2018]. 
Mochammad Ikmal Amirullah dan Apol Pribadi Subriadi / Jurnal SISFO Vol.08 No.02 (2019) 87-98

Halaman ini sengaja dikosongkan 
